\title{
Experimental Measurement of the Temperature Rise Generated During Dynamic Crack Growth in Metals
}

A.J. ROSAKIS, A.T. ZEHNDER* - Graduate Aeronautical Laboratories California Institute of Technology - Pasadena, CA 91125 *Current Affiliation: Department of Theoretical and Applied Mechanics - Cornell University, Ithaca, NY 14853-1503

\section{Abstract}

During the, high speed propagation of cracks, large temperature increases occur at the crack tip due to the intense dissipation of plastic work there. This increased temperature may have a significant effect on the material's dynamic fracture toughness. An experimental investigation of the temperature fields at the tip of dynamically propagating cracks in 4340 steel was performed using a focused array of high speed, infrared detectors. Temperature fields were measured for cracks growing at speeds from $700 \mathrm{~m} / \mathrm{s}$ to $1900 \mathrm{~m} / \mathrm{s}$. Maximum temperature increases were as high as $465^{\circ} \mathrm{C}$. The temperature fields were differentiated to determine the plastic work rate distribution at the crack tip and to estimate the plastic strain rate. Effects of crack tip heating on dynamic fracture toughness are discussed.

\section{Riassunto}

Durante la propagazione ad alta velocità delle cricche, all'apice di queste ultime si verificano forti aumenti di temperatura dovuti ad un'intensa dissipazione locale di lavoro plastico. Tale aumento di temperatura può avere un significativo effetto sulla tenacità di frattura dinamica del materiale. Un'indagine sperimentale dei campi di temperature all'apice delle cricche a propagazione dinamica sull'acciaio 4340 è stata effettuata con l'impiego di una batteria focalizzata di rivelatori IR ad alta velocità. I campi di variazione di temperature sono stati misurati per cricche propagantisi a velocità di $700-1900 \mathrm{~m} / \mathrm{s}$. I massimi incrementi di temperatura arrivavano fino a $465^{\circ} \mathrm{C}$. I campi di temperatura sono stati differenziati per determinare la distribuzione delle velocità di lavoro plastico in corrispondenza dell'apice delle cricche e per valutare la velocità di deformazione plastica. Vengono discussi gli effetti prodotti dal riscaldamento all'apice delle cricche sulla tenacità della frattura dinamica.

\section{Introduction}

It was recognized by Krafft and Irwin[1] that the heat generated at the tip of a dynamically propagating crack may affect the dynamic fracture propagation toughness of a material. The source of the crack tip heating during dynamic crack growth in metals is the dissipation of plastic work near the crack tip. Taylor and Quinney [2] and others, see Bever, et al. [3], have shown that most of the energy of plastic deformation $(>90 \%)$ is dissipated as heat while the remainder is stored in the material in the form of dislocation energy, and energy due to other defects created by the deformation.

Despite the potential importance of crack tip heating on dynamic fracture toughness no attempt to directly measure the temperature at the tip of a crack in a metal has yet been made. Recent advances in infrared detectors now make it possible to measure, in real time, the spatial distribution of crack tip temperature for dynamically propagating cracks.

Such experiments are described here and results for the distribution of temperature and of plastic work rate near the crack tip are discussed. The concept of the experiment is as follows: A linear array of eight high speed, indium antimonide infrared detectors is used to measure the temperature at eight observation points covering a line segment perpendicular to and intersecting the path of a crack propagating dynamically in a specimen of 4340 steel. As the crack traverses the line segment, the voltage outputs from each of the eight detector elements are recorded simultaneously on a set of digital oscilloscopes. At the same time the crack length record is measured using a conductive grid technique. Knowing the temperature versus time at the observation points and using the measured crack length versus time record, the temperature distribution near the crack tip is found. This information is used to assess the role of crack tip heating on fracture toughness, and to determine the plastic work rate. This experimental setup is similar to that developed by Duffy and co-workers [4,5] for studying dynamic shear bands.

\section{Description of experiments}

Electromagnetic radiation is constantly emitted from bodies that are at temperatures greater than 
absolute zero. Since the radiation intensity increse as $\theta^{4}$, where $\theta$ is the asbolute temperature of the body, measurement of radiation can provide a sensitive measurement of temperature. This is the central concept of the experiment described here. As the crack propagates, it heats up the material near the crack tip, causing infrared radiation to be emitted from the specimen surface. By measuring this radiation the temperature may be determined.

\section{Test Specimens}

The specimens used for this experiment were wedge-loaded compact tension specimens of 4340 steel with the dimensions shown in Fig. 1. The mechanical and thermal properties and chemical composition are given in Table 1. The specimens were prepared by grinding, lapping, and then polishing the specimen surfaces with a $9 \mu \mathrm{m}$ diamond paste. Several specimens had side grooves machined along the crack paths. Two side groove geometries were used, a semicircular groove of radius $1.5 \mathrm{~mm}$, and a $\mathrm{V}$-notch groove of width $3 \mathrm{~mm}$ and depth $1.5 \mathrm{~mm}$.

\section{TABLE 1 - Mechanical and thermal properties and chemical composition 4340 steel, aircraft quality, vacuum degassed}

\begin{tabular}{|c|c|c|c|c|c|c|c|c|c|c|c|}
\hline \multicolumn{4}{|c|}{ Heat Treatment } & \multicolumn{2}{|c|}{$\sigma_{0}, \mathrm{MPa}$} & \multicolumn{3}{|c|}{$\mathrm{K}_{\mathrm{IC}}, \mathrm{MPa} \sqrt{\mathrm{m}}$} & \multicolumn{3}{|c|}{ Hardness, HRC } \\
\hline \multicolumn{12}{|c|}{ Quenched and tempered } \\
\hline \multicolumn{4}{|c|}{$\begin{array}{l}871^{\circ} \mathrm{C} 1 \mathrm{hr} ., \text { air cool } \\
843^{\circ} \mathrm{C} 1 \frac{1 / 2}{\mathrm{hr}} ., \text { oil quench } \\
316^{\circ} \mathrm{C} 1 \mathrm{hr} ., \text { air cool }\end{array}$} & \multicolumn{2}{|c|}{$1490 *$} & \multicolumn{3}{|c|}{$50^{*}$} & \multicolumn{3}{|c|}{$44-45$} \\
\hline \multicolumn{12}{|c|}{ Oil quenched } \\
\hline \multicolumn{4}{|c|}{$\begin{array}{l}871^{\circ} \mathrm{C} 1 \mathrm{hr} ., \text { air cool } \\
843^{\circ} \mathrm{C} 1 \frac{1 / 2}{\mathrm{hr}} ., \text { oil quench }\end{array}$} & & & \multicolumn{3}{|c|}{$44 * *$} & \multicolumn{3}{|c|}{$49-55$} \\
\hline \multicolumn{12}{|c|}{ Chemical Composition, \% } \\
\hline $\mathrm{C}$ & $\mathrm{Mn}$ & $\mathrm{P}$ & $\mathrm{S}$ & $\mathrm{Si}$ & $\mathrm{Cu}$ & $\mathrm{Ni}$ & $\mathrm{Cr}$ & Mo & $\mathrm{Sn}$ & $\mathrm{Al}$ & $\mathrm{Fe}$ \\
\hline .42 & .71 & .007 & .013 & .23 & .12 & 1.78 & .83 & .25 & .005 & .033 & Balance \\
\hline
\end{tabular}

Properties at $0{ }^{\circ} \mathrm{C}: * *$

Thermal conductivity

Thermal expansion

Specific heat

density

Thermal diffusivity

$$
\begin{aligned}
& \mathrm{k}=34.6 \mathrm{~W} / \mathrm{m}-{ }^{\circ} \mathrm{K} \\
& \mathrm{a}=11.2 \times 10^{-6}{ }^{\circ} \mathrm{K}^{-1} \\
& \mathrm{c}=448.0 \mathrm{~J} / \mathrm{kg}-{ }^{\circ} \mathrm{K} \\
& \mathrm{Q}=7834 \mathrm{~kg} / \mathrm{m}^{3} \\
& \alpha=.99 \times 10^{-5} \mathrm{~m}^{2} / \mathrm{s}
\end{aligned}
$$

* Source: Zehnder and Rosakis (1989)

** Source: Aerospace Structural Metals Handbook, Metals and Ceramics Information Center, Battelle Columbus Laboratories, Columbus, Ohio, 1989.

An array of lines of conductive paint spaced $3 \mathrm{~mm}$ apart was silkscreened onto the back of each specimen, using techniques developed by Hudak et al. [6]. As the crack runs, the conductive strips are broken, providing a time record of the history of the crack motion. The crack length record is differentiated using the incremental polynomial fit method described by Zehnder and Rosakis [7] to find the crack speed.

The specimens were loaded with a wedge driven slowly between the loading pins until a crack 
was initiated from the initially blunted notch tip. Due to the geometry of the loading and the initial bluntness of the notch, the resulting crack propagates unstably at high speeds ranging from $2000 \mathrm{~m} / \mathrm{s}$ to $1000 \mathrm{~m} / \mathrm{s}$, depending on the initial bluntness.

\section{Infrared detectors}

Based on analytical results of previous authors [8-10] the maximum crack tip temperature increases were anticipated to be in the range of $100^{\circ} \mathrm{C}$ to $1000^{\circ} \mathrm{C}$. At such temperatures the emitted infrared radiation is primarily in the $1 \mu \mathrm{m}$ to $10 \mu \mathrm{m}$ wavelength range. In addition, rise times for the temperatures were expected to be in the $1 \mu$ s to $2 \mu$ s range.

Our choice of indium antimonide (InSb), infrared (IR) detectors was dictated by the wavelength and rise time requirements described above. These detectors are sensitive to radiation with wavelengths from $1 \mu \mathrm{m}$ to $5.5 \mu \mathrm{m}$. The particular system chosen consists of eight $.16 \mathrm{~mm} \times .16 \mathrm{~mm} \mathrm{InSb}$ detector elements in a linear array with a center to center spacing of $0.20 \mathrm{~mm}$. The array is mounted in a liquid nitrogen (LN2) dewar to cool the detectors to $77 \mathrm{~K}$, thus minimizing their electrical noise and maximizing their sensitivity.

Each detector is connected to its own amplifier and the amplified signals are recorded on separate high speed, digital oscilloscopes at a $2 \mathrm{MHz}$ sampling rate. The frequency response of the system of detectors and their amplifiers is from $4 \mathrm{~Hz}$ to $300 \mathrm{kHz}$. The $300 \mathrm{kHz}$ upper limit corresponds to a minimum detectable rise time of $.75 \mu \mathrm{s}$, well below the anticipated 1 to $2 \mu \mathrm{s}$ rise times. Temperature increases as low as $20^{\circ} \mathrm{C}$ could be detected. However, when the temperature increase was less than approximately $50^{\circ} \mathrm{C}$, the signal to noise ratio was on the order of one. Thus accurate data could not be obtained from surfaces at temperatures below $50^{\circ} \mathrm{C}$ above ambient.

\section{Infrared optics}

To measure the crack tip temperature distribution, the infrared radiation must be imaged from eight areas on the specimen surface onto the eight elements of the detector array. The optical system illustrated in Fig. 2 consists of two spherical mirrors and a plane mirror, and was used to focus radiation onto the detectors. The magnification of the optical system is one, and thus the size and spacing of the areas of measurement are equal to that of the detectors. As shown in Fig. 2, the size of the measurement areas is $160 \times 160 \mu \mathrm{m}$, the center to center spacing is $200 \mu \mathrm{m}$ while the total length of the array from end to end is $1.56 \mathrm{~mm}$.

\section{Calibration}

Careful calibration of the system is crucial for obtaining accurate results. The procedure was to heat a sample of the 4340 steel, with the same surface finish as the actual test specimens, in a furnace. The heated sample was removed from the furnace and was placed in front of the optical system such that the specimen was in focus. As the sample cooled the voltage output from the detectors and the sample temperature (measured with a thermocouple) were recorded simultaneously. It was found that the calibration data falls onto a straight line when plotted on a log-log scale.

\section{Experimental results}

Figure 3 shows the time record of the voltage output of each of the eight detector elements, as a crack approaches and passes through the detector points in specimen 9 . Time $t=0$ corresponds to triggering of the oscilloscopes. The material used in this experiment was an oil quenched 4340 steel whose material 
characteristics appear in Table 1. For this experiment and for this particular measurement location, the crack tip speed was approximately constant and equal to $900 \mathrm{~m} / \mathrm{s}$. The maximum voltage increase was recorded by element 4 ( $\mathrm{Ch} 4$.out in the figure). As is clear from the time record corresponding to this channel, the voltage increases rapidly from zero to a maximum value of $16.5 \mathrm{~V}$ in approximately $2 \mu \mathrm{s}$. This rise time is substantially longer than the $0.75 \mu \mathrm{s}$ minimum rise time that can be accurately detected by our measuring system.

The voltage output time histories were converted into temperature histories by means of the calibration relation. Since this relation is non-linear, the resulting temperature records, shown here in Fig. 4, assume a slightly different shape than the voltage records. In this experiment the crack tip traversed the array of detection points slightly off center, but through the region focused on element 4 . This element recorded a maximum temperature increase of $450^{\circ} \mathrm{C}$ while the rise time was $2 \mu \mathrm{s}$. As may be expected by local symmetry, the elements to the left and right of element 4 (channels 3 and 5) recorded temperature increases which are very similar to each other. These elements also had markedly slower rise times than element 4.

Two alternative ways of viewing these results are shown in Figs. 5 and 6. These figures show contours of equal temperature increase near the propagating crack tip. The contours were obtained from the temperature increase versus time results of Fig. 4, by converting the time axis into distance parallel to the direction of crack growth, using the measured crack tip speed of $900 \mathrm{~m} / \mathrm{s}$ and assuming that the crack propagates with a constant velocity.

In both Figs. 5 and 6 the estimated crack tip position is at $\mathrm{x}_{1} \simeq-0.5 \mathrm{~mm}, \mathrm{x}_{2} \simeq 0.6 \mathrm{~mm}$. The length scales of Fig. 5 show that this figure corresponds to a close-up view of temperature increase in the near vicinity of the propagating crack. The isotherms of Fig. 5 clearly show that intense heating (temperatures ranging from $450^{\circ} \mathrm{C}-150^{\circ} \mathrm{C}$ ) extends in a narrow region approximately $1 \mathrm{~mm}$ ahead of the crack tip, while the half width of the resulting wake of temperatures is approximately $0.25 \mathrm{~mm}$. It should be observed that the isotherms in the wake region behind the crack tip remain almost parallel to the crack line for at least $1.5 \mathrm{~mm}$, suggesting that locally, the deformation remains essentially adiabatic (i.e., no substantial cooling by conduction is observed in this scale).

The scale of observation of Fig. 6 is very different. Here we present contours of temperature increase for distances behind the crack tip as large as $60 \mathrm{~mm}$. Here the effect of cooling by conduction becomes apparent by the clear divergence of the isotherms behind the crack tip.

Note that the measurement are performed over small but nevertheless finite areas (see Fig. 2) and that the above contours have been obtained by assigning the recorded temperature history to the center of these areas. It should therefore be recognized that a certain amount of averaging is involved in this measurement. Nevertheless it is expected that the small size areas allow for the accurate investigation of the general structure of the temperature distribution near the tip. On the other hand, this unavoidable averaging makes the recorded maximum temperature increase a lower bound to the actual maximum temperature increase.

\section{Discussion of results}

\section{Plastic work rate}

The distribution of plastic work rate near the crack tip can be obtained by straightforward differentiation of the temperature field. Assuming that the heating due to plastic work is much higher than the thermoelastic effects and treating the crack growth as steady state, the heat conduction equation can be written as 


$$
\mathrm{k} \nabla^{2} \mathrm{~T}+\mathrm{f} \sigma_{\mathrm{ij}} \dot{\varepsilon}_{\mathrm{ij}}^{\mathrm{p}}=-\mathrm{gca} \frac{\partial \mathrm{T}}{\partial \mathrm{x}_{1}}
$$

with respect to a coordinate system translating with the crack tip where $\mathrm{x}_{1}$ is the direction of crack growth, $\mathrm{k}$ is the thermal conductivity, $\mathrm{T}$ is the temperature, $\mathrm{Q}$ is the density, $\mathrm{c}$ is the specific heat, $\mathrm{a}$ is the crack speed, and $\mathrm{f}$ is the fraction of plastic work dissipated as heat.

Note that the conduction term, $\mathrm{k} \nabla^{2} \mathrm{~T}$, in equation (1) involves derivatives of $\mathrm{T}$ with respect to $\mathrm{x}_{3}$, while the measurement provides only $\mathrm{T}\left(\mathrm{x}_{1}, \mathrm{x}_{2}, \mathrm{x}_{3}=\mathrm{h} / 2\right)$ where $\mathrm{h}$ is the specimen thickness. The very short time scales of this measurement $(2-10 \mu \mathrm{s})$ ensure that convection and radiation heat losses from the surface are very small. In addition conduction of heat from the interior of the specimen has no time to affect the surface temperatures near the crack tip. As a result, the variation of $\mathrm{T}$ with respect to $\mathrm{x}_{3}$ is expected to be small, and little error is incurred by neglecting the $\frac{\partial^{2} T}{\partial x_{3}^{2}}$ term in equation (1). Indeed when differentiating $\mathrm{T}\left(\mathrm{x}_{1}, \mathrm{x}_{2}, \mathrm{x}_{3}=\mathrm{h} / 2\right)$ the entire conduction term was found to be small relative to the adiabatic heating term, - $\mathrm{gca} \frac{\partial \mathrm{T}}{\partial \mathrm{x}_{1}}$.

The plastic work rate, $\dot{\mathrm{W}}^{\mathrm{P}}\left(\mathrm{x}_{1}, \mathrm{x}_{2}\right)=\sigma_{\mathrm{ij}} \dot{\varepsilon}_{\mathrm{i} j}^{\mathrm{P}}$, was obtained for all specimens assuming $\mathrm{f}=0.9$ in equation (1). The results presented in Figs. 7 and 8 show the plastic work rate distribution for specimen 9. Figure 7 shows the contours of plastic work rate. The maximum value of the plastic work rate was $600 \times 10^{12} \mathrm{~J} / \mathrm{m}^{3} \mathrm{~s}$. It is seen that $\dot{\mathrm{W}}^{\mathrm{P}}>0$, the region where the active plastic zone is just ahead of the crack tip and is elongated in the $\mathrm{x}_{1}$ direction. The distribution is very symmetric for this particular experiment. The peak of $\dot{\mathrm{W}}^{\mathrm{P}}$ which lies ahead of the crack tip is clearly seen in Fig. 8 where $\dot{\mathrm{W}}^{\mathrm{P}}$ is plotted three dimensionally. This figure shows that except for a few oscillations, $\dot{\mathrm{W}}^{\mathrm{P}}$ is essentially zero everywhere except in a region just ahead of the crack tip.

A rough estimate of the maximum plastic strain rate may be obtained from a simple calculation that assumes a von Mises yield criterion with a constant yield stress $\sigma_{0}$ equal to the static value given in Table 1 for the quenched and tempered steel. In this case

$$
\left\|\dot{\varepsilon}_{\mathrm{ij}}^{\mathrm{P}}(\underset{\mathrm{x}}{\mathrm{x}})\right\|=\frac{\dot{\mathrm{W}}^{\mathrm{P}}(\underline{\mathrm{x}})}{\sigma_{0}} \sqrt{\frac{3}{2}} .
$$

By using the maximum value of the plastic work rate, $\dot{\mathrm{W}}_{\max }^{\mathrm{P}}=600 \times 10^{12} \mathrm{~J} / \mathrm{m}^{3} \mathrm{~s}$. (2) gives maximum strain rate $\left\|\dot{\varepsilon}_{\mathrm{ij}}^{\mathrm{P}}\right\| \max \simeq 7 \times 10^{5} \mathrm{~s}^{-1}$.

\section{Role of Heating on Fracture Toughness}

The experimental data show that temperature increases up to $465^{\circ} \mathrm{C}$ may occur at the tip of dynamically propagating cracks in 4340 steel. Such large temperature increases may have a significant effect on dynamic fracture propagation toughness. Three interacting phenomena that might be affected by local crack tip heating are outlined below. These are the decrease in yield stress at higher temperatures, the change in the fracture mechanism, and the change in the local structure of the near tip fields.

Data from the Metals Handbook on yield stress versus temperature for the tempered 4340 steel indicate that yield stress in tension at $4500^{\circ} \mathrm{C}$ is $50 \%$ lower than that at room temperature. Dislocation motion is thermally activated and will be affected by local crack tip heating even on the time scales of this process, since there is no delay-time associated with the effect of temperature increase on mobility. As a result, near the crack tip there is a possibility of a substantial decrease of yield stress due to local heating. 
A reduced yield stress near the crack tip will cause a change in the crack tip stress and strain fields compared to the fields that would exist under isothermal conditions. If crack growth is governed by a local criterion such as the attainment of a critical strain or opening angle at some distance near the crack tip, the effect of temperature on the local deformation fields will affect the fracture toughness of the material. It is not clear whether such effects will enhance or degrade fracture toughness. In general, lower yield stress values are associated with higher fracture toughness. Although this is true for a limited temperature range, this cannot be extrapolated indefinitely, since in limit as the temperature approaches the melting point, both $\sigma_{0}$ and the fracture toughness must eventually approach zero.

Data of Chi et al. [11] show that dynamic fracture initiation toughness for the tempered 4340 steel at $100^{\circ} \mathrm{C}$ is $50 \%$ higher than at room temperature. Care must be taken in extrapolating this data to apply to dynamic fracture propagation toughness since in performing high temperature fracture initiation tests the material will be held at a high temperature for some time, causing a certain amount of heat treating of the material to occur. However, in dynamic crack growth experiments there is insufficient time for any diffusion of atoms to take place and thus no heat treating can occur.

\section{TABLE 2 - Summary of Experiments}

\begin{tabular}{ccccrc}
\hline Specimen & Heat Treatment & a, mm & $\dot{\mathrm{a}}, \mathrm{m} / \mathrm{s}$ & $\mathrm{T}_{\text {max }} \mathrm{C}$ & Notes \\
\hline 1 & tempered & 29 & 730 & 410 & \\
5 & tempered & 29 & 980 & 415 & \\
7 & oil quenched & 14 & 950 & 185 & shear band temperature \\
9 & oil quenched & 14 & 900 & 450 & \\
12 & oil quenched & 25 & 890 & 425 & \\
13 & oil quenched & 8 & 1300 & 410 & \\
17 & oil quenched & 8 & 1200 & 465 & focused in circular groove \\
21 & oil quenched & 8 & 1100 & $\geq 420$ & Voltage went off scale \\
22 & tempered & 8 & 1900 & 290 & focused in V-notch \\
24 & tempered & 8 & 1140 & 330 & focused in circular groove \\
\hline
\end{tabular}

\section{Conclusions}

In an attempt to predict fracture toughness for dynamic crack growth, isothermal models use fracture criteria implemented very near the crack tip. It is exactly in such regions where the esperimental data show temperature rises as high as $400^{\circ} \mathrm{C}$. In light of the above observation, it appears that thermal effects should be incorporated in such models.

\section{Acknowledgments}

This paper was abstracted from our more complete report, ref. [12]. This work was performed with the support of the Office of Naval Research, through contract N00014-85-K-0596.

\section{References}

[1] Krafft, J.M., and Irwin, G.R., Crack Velocity Considerations, in Fracture Toughness Testing and its 
Applications, ASTM STP 381, 1964.

[2] Taylor, G.I. and Quinney, M.A., The Latent Heat Remaining in a Metal After Cold Work, Proceedings of the Royal Society, Series A, Vol. 143, 1934, pp. 307-326.

[3] Bever, M.B., Holt, D.L., and Titchener, A.L., The Stores Energy of Cold Work, Progress in . Materials Science, Vol. 17, 1973.

[4] Duffy, J. Temperature Measurements During the Formation of Shear Bands in a Structural Steel, in Mechanics of Material Behavior, Dvorak, G.J. (ed.), Elsevier Science Publishers, 1984, pp. 75-86.

[5] Hartley, K.A., Duffy, J., and Hawley, R.H., Measurement of the Temperature Profile during Shear Band Formation in Steels Deforming at High Strain Rates, Journal of the Mechanics and Physics of Solids, Vol. 35, 1987, pp. 283-301.

[6] Hudak, S.J., Dexter, R.D., Aaron, V.D., and Nagy, A., Techniques for Measuring Displacements and Crack Growth During Dynamic Fracture, Southwest Research Institute internal report, 1987.

[7] Zehnder, A.T., and Rosakis, A.J., Dynamic Fracture Initiation and Propagation in 4340 Steel Under Impact Loading, to appear in International Journal of Fracture, 1989.

[8] Weichert, R. and Schönert, K., On the Temperature Rise at the Tip of a Fast Running Crack, Journal of the Mechanics and Physics of Solids, Vol. 22, 1974, pp. 127-133.

[9] Kuang, Z-B., and Atluri, S., Temperature Field due to a Moving Heat Source: A Moving Mesh Finite Element Analysis, Journal of Applied Mechanics, Vol. 52, 1985, pp. 274-280.

[10] Rice, J.R., and Levy, N., Local Heating by Plastic Deformation at a Crack Tip, in The Physics of Strength and Plasticity, A.S. Argon (ed.), MIT Press, 1969, pp. 277-292.

[11] Chi, Y.C., Lee, H.S., and Duffy, J., The Effects of Tempering Temperature and Test Temperature on the Dynamic Fracture Initiation of AISI 4340 VAR Stel, Brown University Report, March 1987.

[12] Zehner, A.T., and Rosakis, A.J., On the Temperature Distribution at the Vicinity of Dynamically Propagating Cracks in 4340 Steel: Experimental Measurements Using High Speed Infrared Detectors, GALCIT report SM89-2, California Institute of Technology, 1989, Journal of the Mechanics and Physics of Solids, Vol. 39, 1991, pp. 385-415.

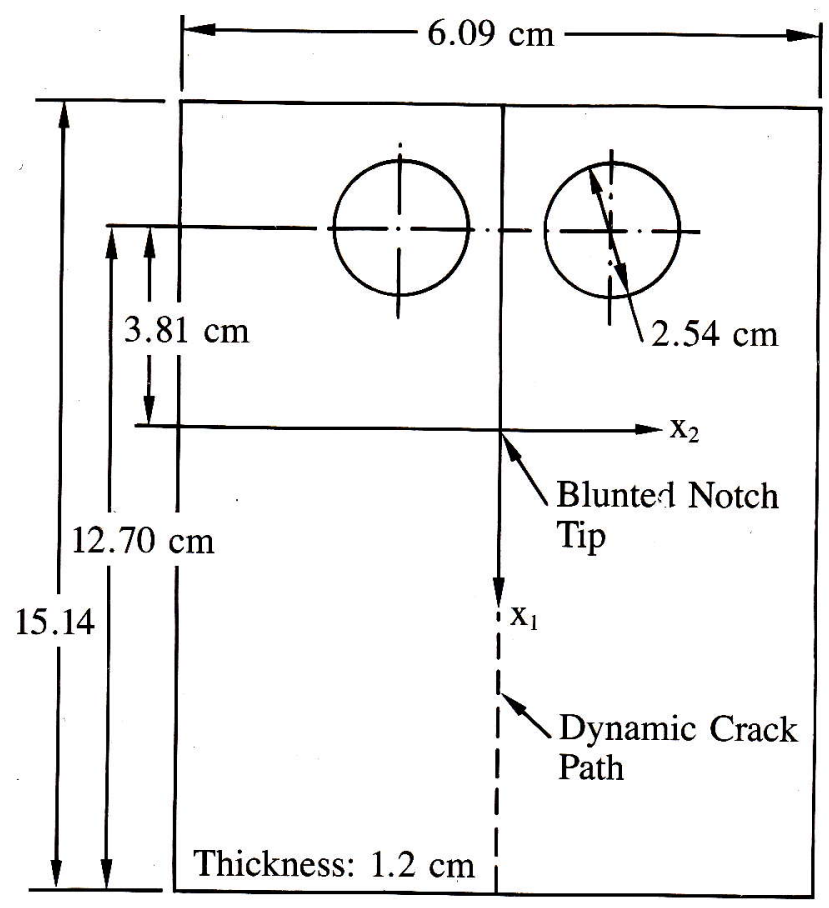




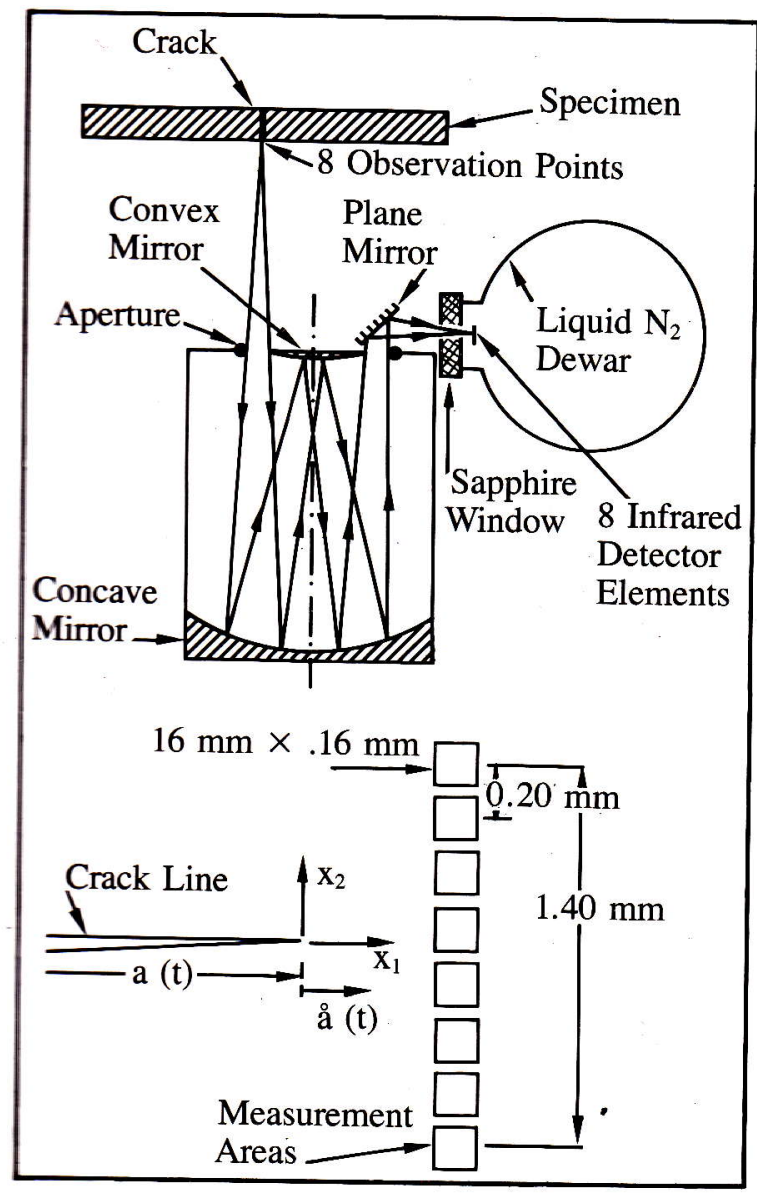

Fig. 2:

Schematic of focusing optics and of points on test specimen from which temperature is measured.

IR9 w/o crosstalk

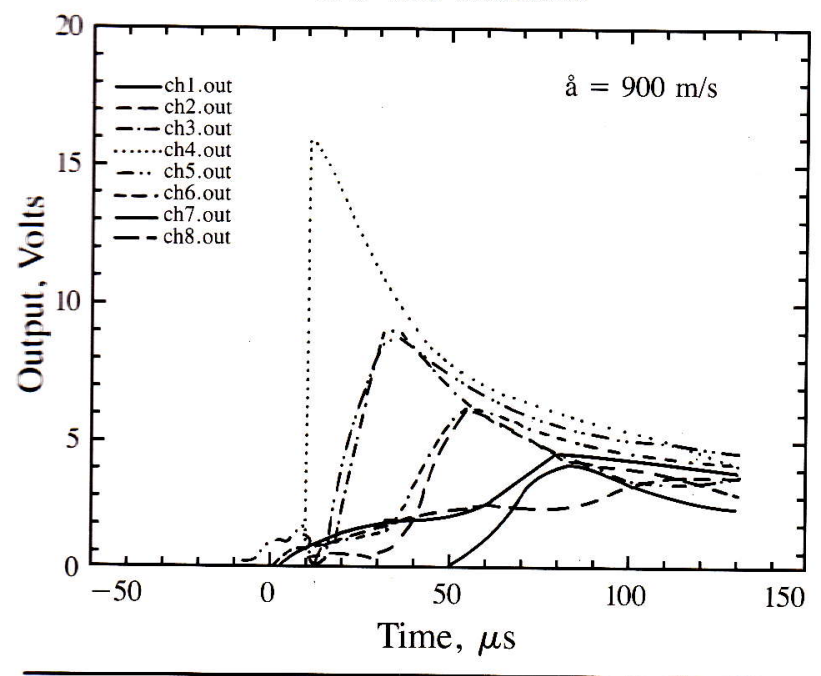

Fig. 3:

Specimen 9, oil quenched steel, IR detector output. Voltage versus time for each element.

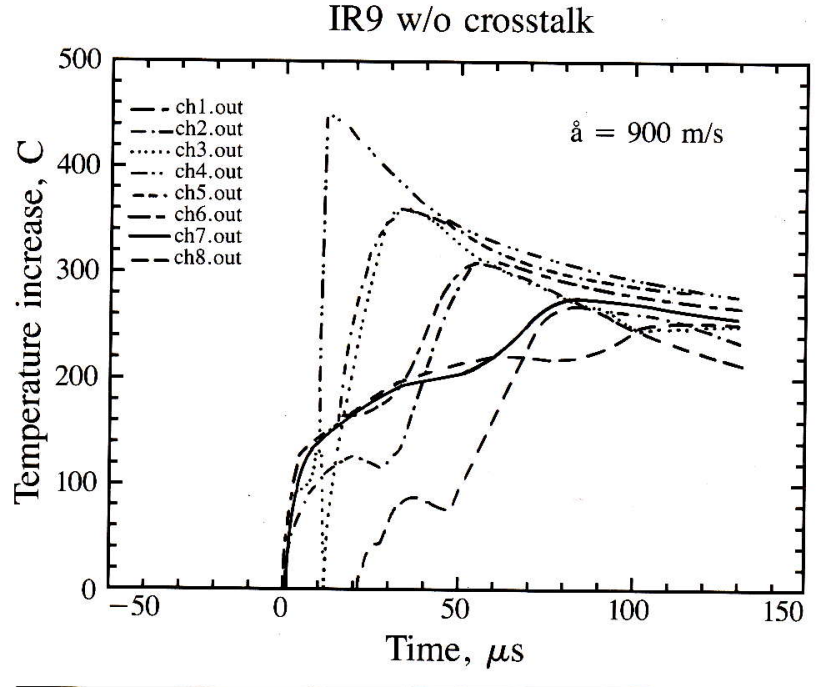

Fig. 4:

Specimen 9, temperature increase over ambient versus rise time for each element.

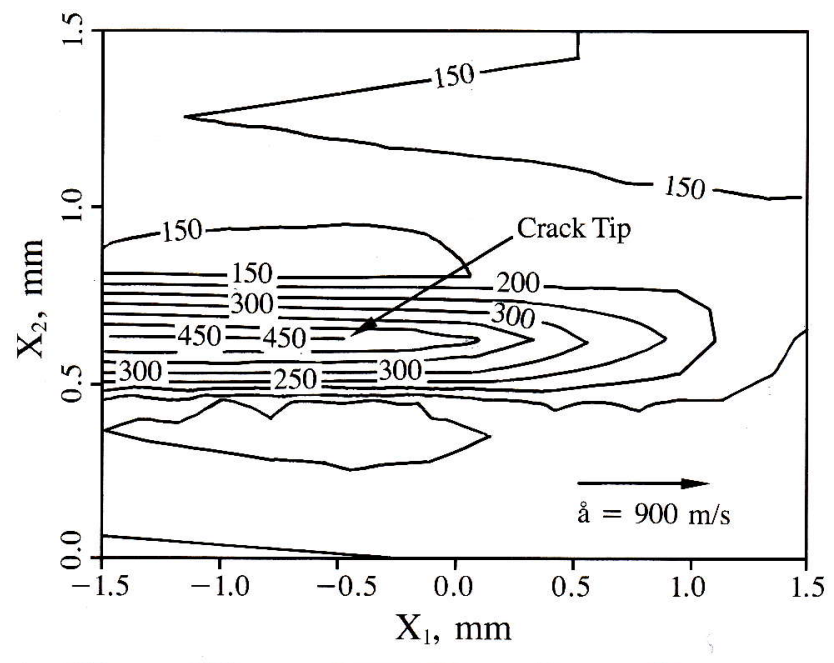

Fig. 5:

Specimen 9, contours of equal temperature rise very near the crack tip. Increment between contours is $25^{\circ} \mathrm{C}$. 


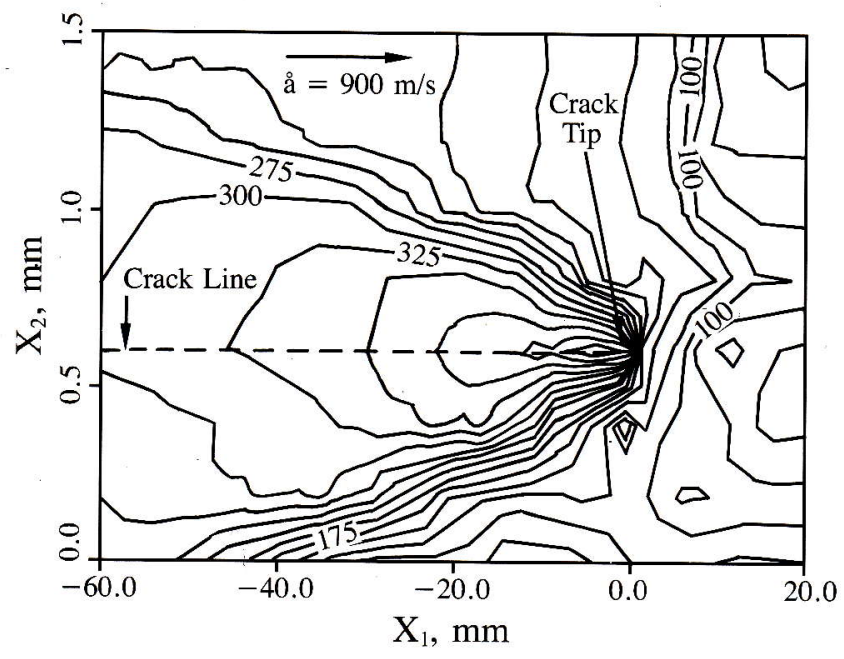

Fig. 6:

Specimen 9, contours of temperature increase over ambient in the region away from the crack tip.

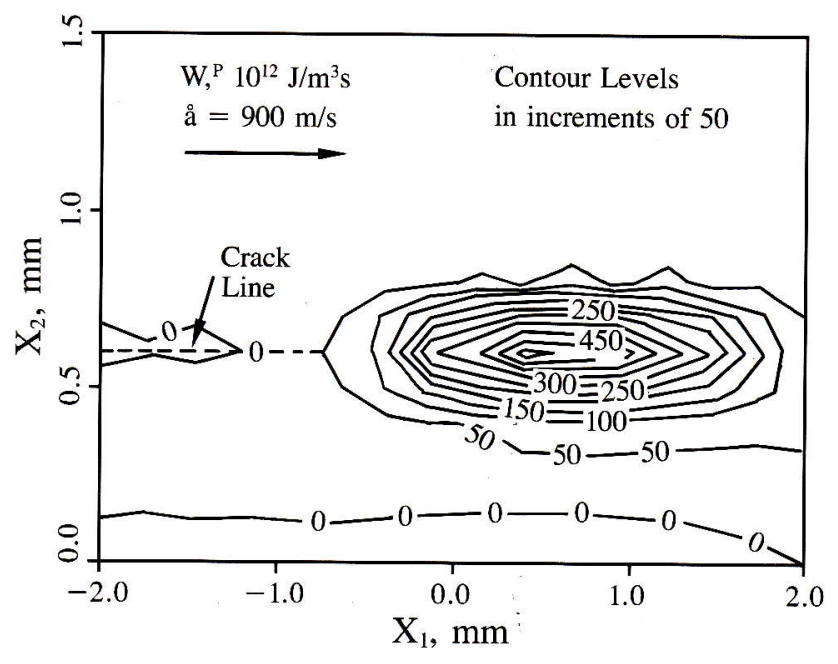

Fig. 7:

Specimen 9, contours of plastic work rate density near crack tip. Increment between contours is $50 \times 10^{12} \mathrm{~J} / \mathrm{m}^{3}-\mathrm{s}$.

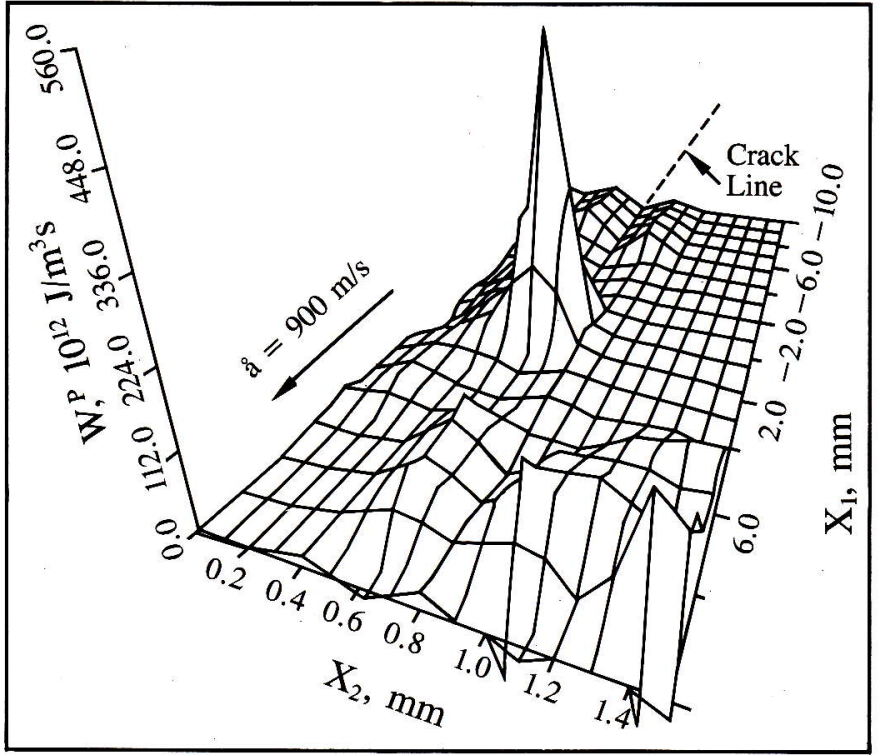

Fig. 8:

Specimen 9, surface plot of plastic work rate density. 